\title{
Infants' maths skills predict their potential
}

Infants who score highly on detecting number changes do better on standard tests by the time they reach preschool.

\section{Katherine Harmon Courage}

21 October 2013 | Corrected: 22 October 2013

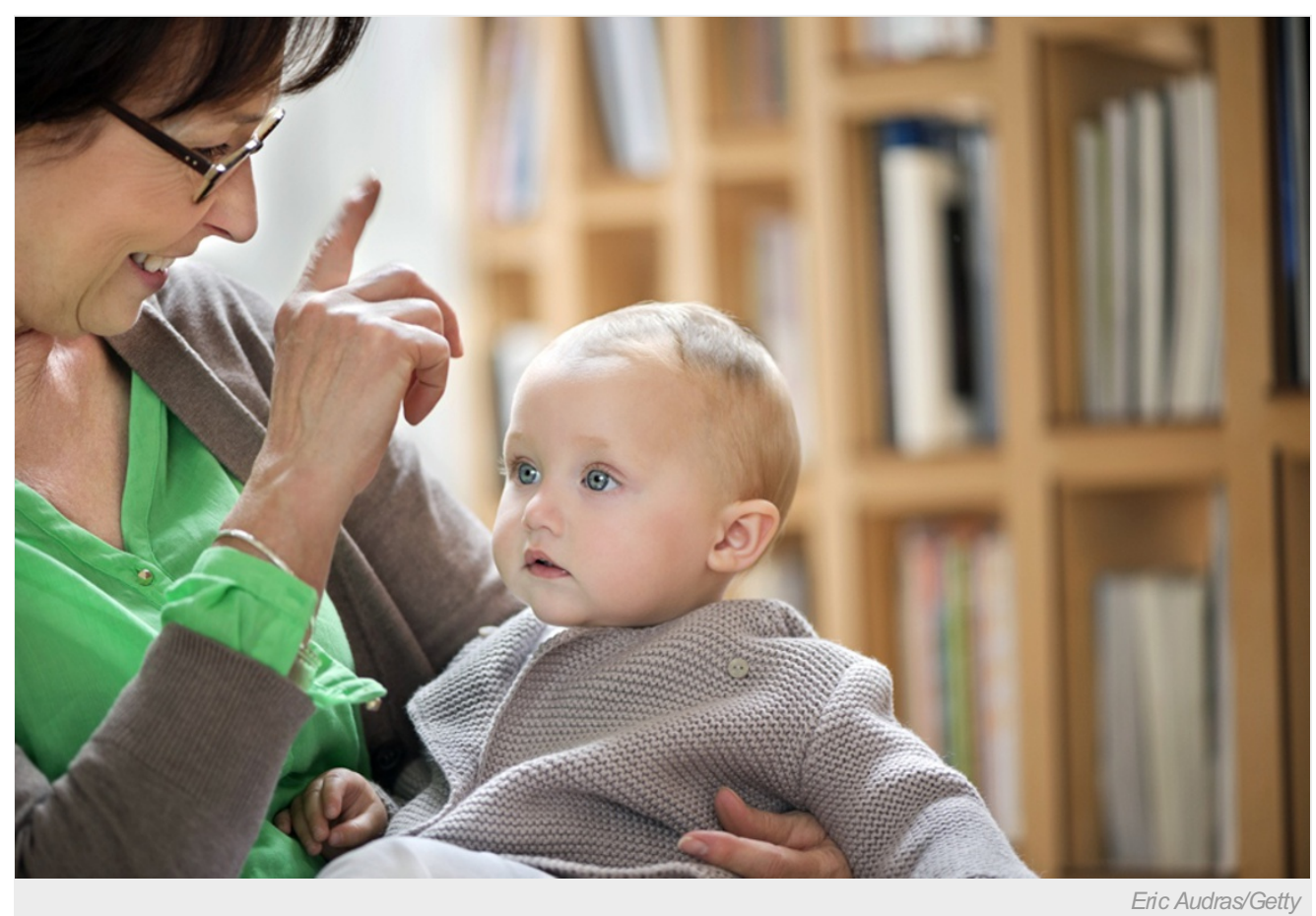

Slx-month-olds already have the ability to sense when a set of objects changes in number — and their skill level predicts their mathematical abilities three years down the line.

An infant's innate sense for numbers predicts how their mathematical aptitude will develop years later, a team of US researchers has found.

Babies can spot if a set of objects increases or decreases in number — for instance, if the number of dots on a screen grows, even when dot size, colour and arrangement also change. But until recently, researchers could generally only determine the number sense of groups of babies, thus ruling out the ability to correlate this with later mathematics skills in individuals.

In 2010, Elizabeth Brannon, a neuroscientist at Duke University in Durham, North Carolina, and her colleagues demonstrated that they could test and track infants' number sense over time ${ }^{1}$. To do this, six-month-old babies are presented with two screens. One shows a constant number of dots, such as eight, changing in appearance, and the other also shows changing dots but presents different numbers of them - eight sometimes and 16 other times, for instance. An infant who has a good primitive number sense will spend more time gazing at the screen that presents the changing number of dots.

In the latest work, which is published in this week's Proceedings of the National Academy of Sciences ${ }^{2}$, Brannon's team took a group of 48 children who had been tested at six months of age and retested them three years later, using the same dot test but also other standard maths tests for preschoolers - including some that assessed the ability to count, to tell which of two numbers is larger and to do basic calculations.

The team found a correlation between the infants' scores for early approximate number systems and later mathematical abilities that is "totally mind blowing", says Justin Halberda, a neuroscientist at Johns Hopkins University in Baltimore, Maryland, who was not involved in the study.

\section{Mathematical minds}

The correlation stands regardless of a child's IQ and performance on non-numerical change-detection tests, which controls for simple 
preference for change. "The fact that there's an association at [six months] is very exciting," says Michèle Mazzocco, a childdevelopment psychologist at the University of Minnesota in Minneapolis.

The findings do not prove that numerical acuity is entirely innate, Brannon notes. Even in the first six months of an infant's life, "there's plenty of opportunity for environmental influence" on mathematical abilities, she says.

A baby's performance on this test will also not determine their later scores on standardized tests, Halberda cautions. Many other factors, including short-term memory, contribute to an adolescent or adult's complex mathematical skills — and these trends can be explored for possible early-maths training. "We have reasons to be excited about our abilities to improve every child's math performance," he says.

Brannon says that the results give stronger evidence that number sense is a building block of mathematical ability. With that in mind, she and her colleagues are now developing games for young children to play on tablet devices, with the goal of boosting their numbersense aptitude ${ }^{3}$.

Nature | doi:10.1038/nature.2013.13982

\section{Corrections}

Corrected:The version published on 21 October incorrectly stated that Mazzocco's team (instead of Brannon's) is developing tablet games for young children.

\section{References}

1. Libertus, M. E. \& Brannon, E. M. Dev. Sci. 13, 900-906 (2010).

2. Starr, A., Libertus, M. E. \& Brannon, E. M. Proc. Natl Acad. Sci. USA http://mww.pnas.org/cgi/doi/10.1073/pnas.1302751110 (2013)

3. Park, J. \& Brannon, E. M. Psychol. Sci. 24, 2013-2019 (2013). 